\title{
GERMINAÇÃO DE SEMENTES DE Mimosa caesalpiniaefolia Benth. EM DIFERENTES SUBSTRATOS E TEMPERATURAS ${ }^{1}$
}

\author{
EDNA URSULINO ALVES ${ }^{2}$, RINALDO CESAR PAULA ${ }^{3}$, ADEMAR PEREIRA OLIVEIRA ${ }^{4}$ \\ RISELANE LUCENA ALCÂNTARA BRUNO ${ }^{4} \mathrm{E}^{\text {ADRIANA ARAÚJO DINIZ }}{ }^{5}$
}

\begin{abstract}
RESUMO - A Mimosa caesalpiniaefolia Benth. é uma espécie nativa da região Nordeste, que vem sendo progressivamente cultivada do Maranhão ao Rio de Janeiro. A planta apresenta grande potencial para arborização, cerca viva e produção de madeira. O presente trabalho teve como objetivo definir o tipo de substrato, a temperatura, o tempo médio e a frequência relativa de germinação, para auxiliar a condução de testes de germinação e vigor em sementes de Mimosa caesalpiniaefolia. Para tanto, realizou-se um experimento no Laboratório de Análise de Sementes do CCA-UFPB, em Areia-PB, em delineamento inteiramente casualizado com os tratamentos distribuídos em esquema fatorial $4 \mathrm{x} 4$, com os fatores temperaturas $\left(20,25,30^{\circ} \mathrm{C}\right.$ constantes e 20 $30^{\circ} \mathrm{C}$ alternadas) e substratos (entre papel, sobre papel, entre areia e entre vermiculita), em quatro repetições de 25 sementes. Foram analisados os seguintes parâmetros: porcentagem de germinação e de plântulas anormais, primeira contagem da germinação e velocidade de germinação, tempo médio e frequência relativa de germinação, massa fresca e massa seca de plântulas. A temperatura de $25^{\circ} \mathrm{C}$ mostrou-se mais adequada para a condução dos testes de germinação e vigor em sementes de Mimosa caesalpiniaefolia, independentemente do substrato utilizado. O substrato entre papel foi o mais apropriado para avaliação da qualidade fisiológica das sementes e a sincronização do processo germinativo foi maior no substrato entre papel, independentemente da temperatura empregada.
\end{abstract}

Termos para indexação: Mimosa caesalpiniaefolia, substrato, temperatura, germinação, vigor.

\section{GERMINATION OF Mimosa caesalpiniaefolia Benth. SEEDS UNDER DIFFERENT SUBSTRATES AND TEMPERATURES}

\begin{abstract}
Mimosa caesalpiniaefolia Benth. is a native species from Northeast region, Brazil, which is cultivated progressively from Maranhão to Rio de Janeiro States. Its presents great potential for arborization, it surrounds it lives and wood production. The present work was realizated with Mimosa caesalpiniaefolia seeds with the objective to determine the substratum type, temperature, the middle time and the relative frequency of germination, for use as a pattern in the conduction of germination and vigor tests. It took place an experiment in the Laboratório de Análise de Sementes do CCA-UFPB, in Areia-PB, in completely randomized design with the treatments distributed in outline factorial $4 \times 4$, temperatures (constant of 20,25 and $30^{\circ} \mathrm{C}$ and alternate of $20-30^{\circ} \mathrm{C}$ ) and substrate (seeds cowered by paper shits, seeds on paper sheets, seeds into sand and seeds into vermiculite) in four replications of 25 seeds. The following parameters were analyzed: germination and of abnormal seedlings (\%) first germination count, germination speed, medium time and relative frequency of germination, fresh matter and weight of dry matter of seedlings. According the results in all substrates the temperature of $25^{\circ} \mathrm{C}$ was most adequate for conduction of germination and
\end{abstract}

\footnotetext{
Aceito para publicação em 30.12.2001.

${ }^{2}$ Aluna do Curso de Pós-graduação em Agronomia, FCAV/UNESP, Jaboticabal-SP; Prof. do Depto. do Depto. de Fitotecnia do CCA/UFPB; e-mail: ednau@mailbr.com.br

${ }^{3}$ Prof., Dr. do Depto. de Produção Vegetal da FCAV/UNESP, Jaboticabal;
}

Via de Acesso Prof. Paulo Donato Castellane, s/n, 14884-900, JaboticabalSP; e-mail: rcpaula@fcav.unesp.br

${ }^{4}$ Profes. Drs. Adjuntos do Depto. de Fitotecnia do CCA/UFPB, Cx. Postal 02, 58397-000, Areia-PB; e-mail: ademar@cca.ufpb.br; lane@cca.ufpb.br ${ }^{5}$ Aluna do curso de graduação em Agronomia do CCA/UFPB. 
vigor tests for Mimosa caesalpiniaefolia seeds. For all temperatures utilized the best germination was observed when the seed were sowed covered bay paper shits.

Index terms: Mimosa caesalpiniaefolia, substrate, temperature, germination, vigor.

\section{INTRODUÇÃO}

A temperatura e o substrato são dois fatores importantes que afetam o comportamento germinativo das sementes. $\mathrm{O}$ substrato é o suporte onde se condicionam as sementes para germinar, cuja função é manter as condições adequadas para germinação e desenvolvimento das plântulas (Piña-Rodrigues \& Vieira, 1988 e Figliolia et al., 1993). Os tipos mais utilizados, descritos e prescritos em Brasil (1992) são: pano, papel toalha, papel de filtro, papel mata borrão, terra vegetal e areia, devendo estar adequadamente úmidos para que forneçam às sementes a quantidade de água necessária à germinação.

Para sementes de espécies florestais, muitos substratos têm sido testados na condução de testes de germinação, tais como carvão, esfagnum, vermiculita, pano, papel toalha, papel de filtro, papel mata borrão, terra vegetal-areia, entre outros (Torres \& Mello, 1994; Bilia et al., 1998; Albuquerque et al., 1998 e Andrade et al., 1999).

As características do substrato (aeração, estrutura, capacidade de retenção de água, infestação por patógenos, etc.) influenciam no processo germinativo, podendo favorecer ou prejudicar a germinação das sementes (Barbosa et al., 1985). O substrato deve manter a disponibilidade de água e a aeração em proporções adequadas (Popinigis, 1985), para evitar a formação de uma película de água envolta da semente, o que restringiria a entrada de oxigênio (Villagomez et al., 1979).

Com relação à temperatura, as sementes apresentam comportamento variável, pois não há uma temperatura ótima e uniforme de germinação para todas as espécies (Borges \& Rena, 1993). Os limites extremos de temperatura de germinação fornecem informações de interesse biológico e ecológico, onde as sementes de diferentes espécies apresentam faixas distintas de temperatura para germinação (Labouriau \& Pacheco, 1978), podendo, dentro dessas faixas, ser considerada como temperatura ótima, aquela em que a maior porcentagem de germinação é obtida, dentro do menor espaço de tempo. Seriam consideradas ainda a mínima e a máxima, respectivamente, como a mais baixa e mais alta temperatura onde a germinação não ocorre (Labouriau \& Pacheco, 1978 e Malavasi, 1988).

De forma geral, a temperatura máxima para a germinação de muitas sementes, encontra-se entre 35 e $40^{\circ} \mathrm{C}$ (Copeland, 1976 e Marcos-Filho, 1986) e a temperatura ótima entre 15 e $30^{\circ} \mathrm{C}$ (Copeland, 1976). No entanto, Marcos-
Filho (1986) e Borges \& Rena (1993) observaram que, a faixa de 20 a $30^{\circ} \mathrm{C}$ têm se mostrado como adequada para a germinação das espécies tropicais e subtropicais e, para Albrecht et al. (1986), a temperatura mais adequada para a germinação da maioria das espécies encontra-se entre 26,5 e $35^{\circ} \mathrm{C}$. Cavalcante \& Perez (1995) estudaram o efeito da temperatura na germinação de sementes de Leucaena leucocephala (Lam.) de Wit. e verificaram que a faixa de máxima germinação foi de 20 a $35^{\circ} \mathrm{C}$. Dentro desta faixa, determinaram $30^{\circ} \mathrm{C}$ como sendo a temperatura ótima de germinação e, 10 e $45^{\circ} \mathrm{C}$, os extremos mínimo e máximo, respectivamente.

Quanto à influência de baixas temperaturas na germinação das sementes de muitas espécies, Mayer \& PoljakoffMayber (1989) relataram que as razões são obscuras. No entanto, várias explicações foram sugeridas, tais como inativação de enzimas ou processos de mudanças de fase. Hendricks \& Taylorson (1976) também sugeriram que as baixas temperaturas podem reduzir as taxas metabólicas até que as vias essenciais para o início da germinação não possam mais operar.

Vários estudos também têm demonstrado, ainda, que a temperatura interage com hormônios vegetais, de forma a alterar seus níveis endógenos e por conseguinte influenciar e regular o processo germinativo (Bewley \& Black, 1985). Alguns reguladores de crescimento têm a propriedade de modificar as exigências de temperatura e induzir a germinação de sementes de algumas espécies (Reynolds \& Thompson, 1973). Dessa forma, os autores acrescentam que a falta de germinação pode ser devida à presença de inibidor(es) ativo(s) e/ou deficiência de promotor(es) essencial (ais) nessas sementes. Davies (1988) relatou que um estimulador de germinação, como a temperatura ou o hormônio pode induzir a germinação por redução do conteúdo de inibidor(es) e/ou por aumento do conteúdo de promotor(es).

O objetivo do presente trabalho foi definir o tipo de substrato, a temperatura, o tempo médio de germinação e a frequência relativa para auxiliar na condução dos testes de germinação e vigor em sementes de Mimosa caesalpiniaefolia Benth.

\section{MATERIAL E MÉTODOS}

O trabalho foi realizado no Laboratório de Análise de Sementes do Centro de Ciências Agrárias da Universidade Federal da Paraíba, entre agosto e setembro de 2001, com 
sementes de Mimosa caesalpiniaefolia, colhidas em dez árvores no município de Areia-PB., em novembro de 2000. Os frutos, de coloração café, segundo a carta de cores de Muñoz et al. (1993) foram colhidos diretamente das árvores e beneficiados manualmente. O beneficiamento constou da abertura dos mesmos para obtenção das sementes, com eliminação daquelas mal formadas. A sementes foram armazenadas em latas de alumínio fechadas hermeticamente e deixadas em câmara fria com temperatura em torno de $10^{\circ} \mathrm{C}$ e umidade relativa do ar de $60 \%$. A umidade inicial das sementes era de $8 \%$ e não verificou-se variações no momento de instalação dos testes.

O teste de germinação foi instalado com os substratos sobre papel e entre papel "germitest", entre areia, com granulometria em torno de $0,5-1,0 \mathrm{~mm}$ e entre vermiculita, nas temperaturas constantes de 20,25 e $30^{\circ} \mathrm{C}$ e alternadas de $20-30^{\circ} \mathrm{C}$, em caixa plástica transparente de $11 \times 11 \times 3 \mathrm{~cm}, \mathrm{com}$ tampa, em quatro repetições de 25 sementes e fotoperíodo de oito horas. O papel foi umedecido com água destilada na quantidade equivalente a 2,5 vezes o seu peso seco e o substrato areia (cerca de $500 \mathrm{~g}$ ) e vermiculita (cerca de $200 \mathrm{~g}$ ) com $80 \mathrm{ml}$ de água destilada. As contagens foram feitas diariamente, considerando germinadas as sementes cuja raiz primária rompeu o tegumento e atingiu pelo menos $2 \mathrm{~cm}$ de comprimento. De posse do número de sementes germinadas diariamente, avaliou-se as seguintes características: primeira contagem da germinação - correspondente a porcentagem acumulada de sementes germinadas até o terceiro dia após o início do teste conforme Martins et al. (1992); índice de velocidade de germinação (IVG) - determinado de acordo com a fórmula apresentada por Maguire (1962); germinação - considerou-se, ao final do teste (oito dias), as plântulas normais que apresentavam as estruturas essenciais perfeitas (Brasil, 1992); plântulas anormais - determinada de acordo com Carvalho \& Nakagawa (2000); tempo médio e frequência relativa de germinação - de acordo com Labouriau \& Valadares (1976); massa fresca e massa seca de plântulas - submetendo-se as plântulas normais a pesagem imediata, após a contagem no teste de germinação e a secagem em estufa regulada a $80^{\circ} \mathrm{C}$ por 24 horas, respectivamente, sendo os resultados expressos em massas fresca e seca (g) por repetição, conforme recomendações de Vieira \& Carvalho (1994).

A análise estatística dos dados foi realizada, segundo o delineamento experimental inteiramente casualizado, com os tratamentos distribuídos em esquema fatorial $4 \mathrm{x} 4$, com os fatores temperaturas (constantes de 20,25 e $30^{\circ} \mathrm{C}$ e alternadas de $20-30^{\circ} \mathrm{C}$ ) e substratos (sobre papel e entre papel "germitest", entre areia e vermiculita) e foram submetidos à análise de variância, sem transformações e as médias comparadas pelo teste de Tukey, a 5\% de probabilidade, quando houve significância no teste $\mathrm{F}$.

\section{RESULTADOS E DISCUSSÃO}

As médias da porcentagem de germinação e das plântulas anormais, encontram-se nas Tabelas 1 e 2, onde se verificam as interações significativas entre substrato e temperatura, indicando que existe pelo menos uma combinação ideal entre estes dois fatores, que otimiza a porcentagem de germinação e a porcentagem das plântulas anormais. Essas interações são importantes, já que a capacidade de retenção de água e a quantidade de luz que o substrato permite chegar à semente podem ser responsáveis por diferentes respostas germinativas, até para a mesma temperatura (Figliolia et al., 1993). Estes resultados corroboram com aqueles obtidos com sementes de Cedrela fissilis Vell. e Cordia trichotoma (Vell.) Arrab. ex Steud. (Alcalay \& Amaral, 1981), Torresia acreana Ducke (Albrecht et al., 1986), Bixa orellana L. (Gomes \& Bruno, 1992), Cedrela odorata L. (Andrade \& Pereira, 1994), Acacia mangium Willd (Lima \& Garcia, 1996), Ocotea corymbosa (Meissn.) Mez (Bilia et al., 1998), Colubrina glandulosa Perk (Albuquerque et al., 1998) e Sebastiania commersoniana (Baill.) Smith. \& Downs (Santos \& Aguiar, 2000) e discordam dos resultados de Pereira \& Andrade (1994), com sementes de Psidium guajava L e Passiflora edulis Sims. e de Andrade et al. (1999) com sementes de Euterpe edulis Mart.

As maiores porcentagens de germinação de sementes de Mimosa caesalpiniaefolia ocorreram na temperatura de $25^{\circ} \mathrm{C}$, com os substratos sobre papel e entre vermiculita; a 25 e a $30^{\circ} \mathrm{C}$, entre papel; a 25,30 e $20-30^{\circ} \mathrm{C}$ entre areia. Contudo, a $25^{\circ} \mathrm{C}$ não houve diferença estatística entre os substratos. A 20 e a $30^{\circ} \mathrm{C}$, os melhores substratos foram entre papel e entre areia e, na temperatura alternada de $20-30^{\circ} \mathrm{C}$, o substrato entre areia mostrou-se superior aos demais. Trabalhando com sementes de Mimosa caesalpiniaefolia, provenientes de Petrolina-PE, Torres et al. (1994) verificaram que a temperatura de $20-30^{\circ} \mathrm{C}$ e o uso do substrato sobre papel mata borrão foram responsáveis pelas maiores porcentagens de germinação, também Gonçalves et al. (2000) recomendam as temperaturas de 27 ou $20-30^{\circ} \mathrm{C}$ como adequadas para geminação de sementes da mesma espécie, oriundas de Tatuí-SP. A temperatura de $20-30^{\circ} \mathrm{C}$ e o uso do rolo de papel como substrato também foram recomendados por Santos et al. (1999) para sementes de Passiflora edulis Sims f. flavicarpa Deg. e Medeiros et al. (2001) para sementes de Aegiphila sellowiana Cham. Resultados estes corroborados por Santos \& Aguiar 
TABELA 1. Porcentagem de germinação de sementes de Mimosa caesalpiniaefolia Benth., submetidas a diferentes temperaturas $\mathrm{e}$ substratos.

\begin{tabular}{|c|c|c|c|c|}
\hline \multirow{3}{*}{ Substratos } & \multicolumn{4}{|c|}{ Germinação (\%) } \\
\hline & \multicolumn{4}{|c|}{ Temperaturas $\left({ }^{\circ} \mathrm{C}\right)$} \\
\hline & 20 & 25 & 30 & $20-30$ \\
\hline Sobre papel & $76 \mathrm{bcB}$ & $99 \mathrm{aA}$ & 31 c D & 49 c C \\
\hline Entre papel & $88 \mathrm{aB}$ & $99 \mathrm{aA}$ & $90 \mathrm{a} A B$ & $81 \mathrm{~b} \mathrm{~B}$ \\
\hline Entre areia & $84 a b B$ & $96 \mathrm{aA}$ & $96 a \mathrm{~A}$ & $91 \mathrm{aAB}$ \\
\hline Entre vermiculita & 72 c B & $92 \mathrm{aA}$ & $68 \mathrm{~b} \mathrm{~B}$ & 52 c C \\
\hline Valor de F para substrato (S) & & $124,60^{* *}$ & & \\
\hline Valor de F para temperatura $(\mathrm{T})$ & & $105,45^{* *}$ & & \\
\hline Valor de F para interação $(\mathrm{SxT})$ & & $33,59 * *$ & & \\
\hline CV (\%) & & 6,26 & & \\
\hline
\end{tabular}

Médias seguidas pela mesma letra, minúscula na coluna e maiúscula na linha, não diferem entre si, pelo teste de Tukey, a $5 \%$

TABELA 2. Porcentagem de plântulas anormais de Mimosa caesalpiniaefolia Benth., submetidas a diferentes temperaturas e substratos.

\begin{tabular}{|c|c|c|c|c|}
\hline \multirow{3}{*}{ Substratos } & \multicolumn{4}{|c|}{ Plântulas anormais (\%) } \\
\hline & \multicolumn{4}{|c|}{ Temperaturas $\left({ }^{\circ} \mathrm{C}\right)$} \\
\hline & 20 & 25 & 30 & $20-30$ \\
\hline Sobre papel & $24 \mathrm{aC}$ & $1 \mathrm{aD}$ & $68 \mathrm{aA}$ & $51 \mathrm{aB}$ \\
\hline Entre papel & $12 \mathrm{c} \mathrm{A}$ & $1 \mathrm{aB}$ & 10 c A & 18 c A \\
\hline Entre areia & $15 \mathrm{bc} \mathrm{A}$ & $4 \mathrm{aB}$ & d B & $\mathrm{d} A B$ \\
\hline Entre vermiculita & $23 \mathrm{ab} \mathrm{B}$ & $2 \mathrm{aC}$ & $30 \mathrm{~b} \mathrm{AB}$ & $35 \mathrm{~b} \mathrm{~A}$ \\
\hline Valor de F para substrato (S) & \multicolumn{3}{|c|}{$136,55 * *$} & \\
\hline Valor de F para temperatura $(\mathrm{T})$ & \multicolumn{3}{|c|}{$113,88 * *$} & \\
\hline Valor de F para interação (SxT) & \multicolumn{3}{|c|}{$38,21 * *$} & \\
\hline $\mathrm{CV}(\%)$ & \multicolumn{3}{|c|}{23,95} & \\
\hline
\end{tabular}

Médias seguidas pela mesma letra, minúscula na coluna e maiúscula na linha, não diferem entre si, pelo teste de Tukey, a $5 \%$

(2000) que também obtiveram os melhores resultados de germinação de sementes de Sebastiania commersoniana (Baill.) Smith. \& Downs na temperatura alternada de $20-30^{\circ} \mathrm{C}$ e com o substrato sobre areia.

A faixa de temperatura de $20^{\circ} \mathrm{C}$ mostrou-se adequada para a condução dos testes de germinação de sementes de Callistephus chinensis Nees. (Carneiro, 1996) e Ocotea catharinensis Mez (Silva \& Aguiar, 1998); de $25^{\circ} \mathrm{C}$ para sementes de Stevia rebaudiana (Bert.) Bertoni (Randi, 1981; Carneiro et al., 1987 e Takahashi et al., 1996), Gmelina arborea Roxb. (Cavallari et al., 1992), Euterpe edulis Mart. (Andrade et al., 1999) e Seguieria langsdorffii Moq. (Rêgo et al., 2001c); de $30^{\circ} \mathrm{C}$ para sementes de sementes de Stevia rebaudiana (Bert.) Bertoni (Sakaguchi \& Kan, 1982), Ocotea corymbosa (Meissn.) Mez. (Bilia et al., 1998), Desmodium incanum DC. (Baseggio \& Franke, 1998) e Maquira sclerophylla (Ducke) C.C.Berg. (Miranda \& Ferraz, 1999); de 25, 20-30 e $30^{\circ} \mathrm{C}$ para sementes de Colubrina glandulosa Perk (Albuquerque et al., 1998) e de $25-35^{\circ} \mathrm{C}$ para sementes de Tabebuia chrysotricha (Mart.ex DC.) Standl (Nogueira, 2001).

Independentemente do substrato utilizado, em geral, a temperatura de $25^{\circ} \mathrm{C}$ proporcionou as menores porcentagens de plântulas anormais. Contudo, quando foi utilizado o substrato entre areia, os resultados obtidos a $25,30 \mathrm{e}$ $20-30^{\circ} \mathrm{C}$, foram estatisticamente iguais. A $20^{\circ} \mathrm{C}$ as menores porcentagens de plântulas anormais foram encontradas nos substratos entre papel e entre areia e, a 30 e a $20-30^{\circ} \mathrm{C}$, o substrato entre areia proporcionou os menores valores. À semelhança do que foi observado para a germinação, a $25^{\circ} \mathrm{C}$ não houve diferença entre os substratos para porcentagem de plântulas anormais. Resultados semelhantes foram obtidos por Miranda \& Ferraz (1999) com sementes de Maquira sclerophylla (Ducke) C.C. Berg. ao verificarem as menores porcentagens de plântulas anormais nas temperaturas de $10,20,25$ e $30^{\circ} \mathrm{C}$. Eles comentam que a 15 e $35^{\circ} \mathrm{C}$ ocorreu a formação de plântulas anormais (raiz primária pouco desenvolvida com extremidade necrosada, pouca ou nenhuma raiz secundária, epicótilo atrofiado, eófilos reduzidos e/ou necrosados).

Estudos realizados por Figueiredo \& Popinigis (1980) indicaram que a $30^{\circ} \mathrm{C}$ ocorreram as menores porcentagens de plântulas anormais de Urena lobata L. Semelhantemente, Braga et al. (1999) observaram que as temperaturas de 20, 30 e $30-35^{\circ} \mathrm{C}$ foram responsáveis pelas menores porcentagens de plântulas anormais de Borojoa sorbilis (Duque) Cuatre, sendo as maiores constatadas a 25 e $30-35^{\circ} \mathrm{C}$.

Nas Tabelas 3 e 4, estão as comparações entre as médias da primeira contagem e do índice de velocidade de germinação de sementes submetidas a diferentes substratos e temperaturas. Para os dados da primeira contagem da germinação, 
TABELA 3. Primeira contagem da germinação de sementes de Mimosa caesalpiniaefolia Benth., submetidas a diferentes temperaturas e substratos.

\begin{tabular}{|c|c|c|c|c|}
\hline \multirow{3}{*}{ Substratos } & \multicolumn{4}{|c|}{ Primeira contagem da germinação (\%) } \\
\hline & \multicolumn{4}{|c|}{ Temperaturas $\left({ }^{\circ} \mathrm{C}\right)$} \\
\hline & 20 & 25 & 30 & $20-30$ \\
\hline Sobre papel & $95 \mathrm{aA}$ & $100 \mathrm{aA}$ & $80 \mathrm{~b} \mathrm{~B}$ & $71 \mathrm{~b} \mathrm{C}$ \\
\hline Entre papel & $100 \mathrm{aA}$ & $100 \mathrm{aA}$ & $96 \mathrm{aA}$ & $97 \mathrm{aA}$ \\
\hline Entre areia & $32 \mathrm{c} \mathrm{C}$ & $93 \mathrm{ab} A$ & 64 c B & $29 \quad \mathrm{c} \mathrm{C}$ \\
\hline Entre vermiculita & $55 \mathrm{~b} \mathrm{~B}$ & 89 b A & $\mathrm{d} C$ & 36 c C \\
\hline Valor de F para substrato $(\mathrm{S})$ & & $188,14 * *$ & & \\
\hline Valor de F para temperatura $(\mathrm{T})$ & & $188,14 * *$ & & \\
\hline Valor de F para interação (SxT) & & $49,50 * *$ & & \\
\hline CV (\%) & & 6,40 & & \\
\hline
\end{tabular}

Médias seguidas pela mesma letra, minúscula na coluna e maiúscula na linha, não diferem entre si, pelo teste de Tukey, a $5 \%$.

TABELA 4. Índice de velocidade de germinação (IVG) de plântulas de Mimosa caesalpiniaefolia Benth., submetidas a diferentes temperaturas e substratos.

\begin{tabular}{|c|c|c|c|c|}
\hline \multirow{3}{*}{ Substratos } & \multicolumn{4}{|c|}{ IVG } \\
\hline & \multicolumn{4}{|c|}{ Temperaturas $\left({ }^{\circ} \mathrm{C}\right)$} \\
\hline & 20 & 25 & 30 & $20-30$ \\
\hline Sobre papel & 11,29 b B & $12,50 \mathrm{aA}$ & 10,83 b B & 9,39 b C \\
\hline Entre papel & $12,25 \mathrm{a} \mathrm{A}$ & $12,50 \mathrm{aA}$ & 11,91 a A & $11,76 \mathrm{aA}$ \\
\hline Entre areia & 6,60 & 10,91 b A & 9,69 & 6,86 с C \\
\hline Entre vermiculita & 7,85 с $B$ & $9,38 \quad$ c $A$ & 7,10 & 6,21 c C \\
\hline Valor de F para substrato (S) & & $341,44 * *$ & & \\
\hline Valor de F para temperatura $(\mathrm{T})$ & & $103,40 * *$ & & \\
\hline Valor de F para interação (SxT) & & $18,21^{* *}$ & & \\
\hline CV (\%) & & 4,61 & & \\
\hline
\end{tabular}

Médias seguidas pela mesma letra, minúscula na coluna e maiúscula na linha, não diferem entre si, pelo teste de Tukey, a $5 \%$.

os maiores valores ocorreram nas temperaturas de 20 e $25^{\circ} \mathrm{C}$ e o uso do substrato sobre papel; no substrato entre papel ocorreram, em geral, os maiores valores da primeira contagem, não havendo, porém, diferenças entre as temperaturas; para os substratos entre areia e entre vermiculita a temperatura de $25^{\circ} \mathrm{C}$ proporcionou os melhores resultados. Avaliandose o efeito dos substratos, em cada uma das temperaturas, observa-se que a $20^{\circ} \mathrm{C}$, os maiores valores da primeira contagem ocorreram sobre papel e entre papel; a $25^{\circ} \mathrm{C}$ e entre vermiculita, foi observado o pior resultado; a $30^{\circ} \mathrm{C}$ e a $20-30^{\circ} \mathrm{C}$, o substrato entre papel proporcionou resultados superiores aos demais. Tais resultados concordam com os obtidos por Andrade \& Pereira (1994) com sementes de Cedrela odorata L. que recomendam os substratos sobre papel a $25^{\circ} \mathrm{C}$ ou rolo de papel a $30^{\circ} \mathrm{C}$.
Carneiro et al. (1996) trabalhando com sementes de Callistephus chinensis Nees constataram que a temperatura de $25^{\circ} \mathrm{C}$ e os substratos sobre solo arenoso ou papel germitest foram responsáveis pelos maiores valores da primeira contagem da germinação, semelhantemente, Andrade \& Pereira (1994) verificaram que os melhores resultados da primeira contagem de sementes de Cedrela odorata L. foram com os substratos sobre papel a $25^{\circ} \mathrm{C}$ ou rolo de papel a $30^{\circ} \mathrm{C}$. Em sementes de Acacia mangium Willd., Lima \& Garcia (1996) observaram que o substrato rolo de papel proporcionou os melhores valores da primeira contagem da germinação, independentemente da temperatura $\left(25,25-35\right.$ e $\left.35^{\circ} \mathrm{C}\right)$ utilizada.

$\mathrm{O}$ índice de velocidade de germinação (IVG) foi maior quando se utilizou o substrato entre papel, a $20^{\circ} \mathrm{C}$, entre papel e sobre papel, a $25^{\circ} \mathrm{C}$, e entre papel a 30 e $20-30^{\circ} \mathrm{C}$. Em 
geral, dentro de cada substrato, a temperatura de $25^{\circ} \mathrm{C}$ proporcionou os maiores valores de IVG, exceto quando o substrato utilizado foi entre papel, situação na qual não foi observada diferença entre as temperaturas. De forma semelhante, Carneiro (1996) observou que a temperatura de $20^{\circ} \mathrm{C}$ foi responsável pelos maiores valores de IVG de sementes de Callistephus chinensis Nees, enquanto Andrade et al. (1999) verificaram que os maiores valores de IVG em sementes de Euterpe edulis Mart. foi a $20-30^{\circ} \mathrm{C}$ e $25^{\circ} \mathrm{C}$ e usando o substrato entre vermiculita. Para sementes de Cariniana legalis Mart. (Rêgo et al., 2001a) foi a temperatura de $20-30^{\circ} \mathrm{C}$ e os substratos solo de floresta, solo comercial, vermiculita e rolo de papel e a mesma temperatura com o substrato solo de floresta para sementes de Dalbergia nigra Vellozo (Rêgo et al., 2001b).

Andrade \& Pereira (1994) verificaram que os melhores resultados de IVE em sementes de Cedrela odorata L. com o uso dos substratos sobre papel foi a $25^{\circ} \mathrm{C}$ ou rolo de papel a $30^{\circ} \mathrm{C}$. Figueiredo \& Popinigis (1980) relataram que a maior velocidade de crescimento das plântulas de Urena lobata L. foi a $30^{\circ} \mathrm{C}$, entretanto, em sementes de Acacia mangium Willd., Lima \& Garcia (1996) observaram que o substrato rolo de papel a $35^{\circ} \mathrm{C}$ proporcionou maior velocidade de germinação.

A germinação das sementes se distribui de forma diferente, nas temperaturas e nos substratos, ao longo do tempo (Figura 1). Os polígonos de frequência relativa são claramente unimodais para os substratos entre e sobre papel, nas quatro temperaturas utilizadas, como também para os substratos entre areia e entre vermiculita na temperatura de $25^{\circ} \mathrm{C}$. Nos demais substratos, incluindo sobre papel na temperatura de $30^{\circ} \mathrm{C}$, tornam-se claramente polimodais. Resultados semelhantes foram obtidos por Fanti \& Perez (1999) com sementes de Adenanthera pavonina L., onde o substrato papel também proporcionou distribuição unimodal de frequência.

Observa-se um desvio do tempo de germinação à esquerda da moda principal da distribuição das frequências nos substratos entre areia, nas temperaturas de 20 e $20-30^{\circ} \mathrm{C}$ e entre vermiculita, na temperatura de $30^{\circ} \mathrm{C}$ e a direita para os demais substratos, independentemente da temperatura utilizada. A assimetria da distribuição pode mostrar que a heterogeneidade é devida a demora ou a uma rapidez na germinação das sementes, ou a ambos os casos, dependendo da temperatura e do substrato empregado. Desvios de tempo de germinação para a esquerda foram relatados por Cavalcante \& Perez (1995) e para a direita por Perez et al. (1998) e Fanti \& Perez (1999).

Nassif \& Perez (2000) estudaram os efeitos de diferentes temperaturas $\left(\right.$ de $9^{\circ} \mathrm{C}$ até $45^{\circ} \mathrm{C}$, com intervalos de $30^{\circ} \mathrm{C}$ ) na germinação de sementes de Pterogyne nitens Tull. e observaram que a distribuição da frequência ocorreu de forma diferenciada, com desvio do tempo de germinação para a direita da moda principal. Para outras espécies como Prosopis juliflora (Sw.) DC. (Perez \& Moraes, 1990), Adenanthera pavonina L. (Zpevak, 1994), Stryphnodendron polyphyllum Mart. (Tambelini, 1994), Leucaena leucocephala (Lam.) de Wit (Cavalcante \& Perez, 1995) e Pterogyne nitens Tul. (Nassif \& Perez, 2000), os polígonos de frequência também não apresentaram distribuição normal.

As médias de massa fresca e de massa seca de plântulas, encontram-se nas Tabelas 5 e 6 . A massa fresca de plântulas de Mimosa caesalpiniaefolia foi maior na temperatura de $25^{\circ} \mathrm{C}$, independente do substrato utilizado, comparativamente às outras temperaturas. Os substratos entre areia e entre

TABELA 5. Massa fresca de plântulas de Mimosa caesalpiniaefolia Benth., submetidas a diferentes temperaturas e substratos.

\begin{tabular}{|c|c|c|c|c|}
\hline \multirow{3}{*}{ Substratos } & \multicolumn{4}{|c|}{ Massa fresca $(\mathrm{g})$} \\
\hline & \multicolumn{4}{|c|}{ Temperaturas $\left({ }^{\circ} \mathrm{C}\right)$} \\
\hline & 20 & 25 & 30 & $20-30$ \\
\hline Sobre papel & 0,7203 & 1,4108 b A & 0,2780 & 0,4568 \\
\hline Entre papel & 1,0453 b B & 1,5738 b A & $1,0460 \quad$ c B & 0,8573 b B \\
\hline Entre areia & $1,4415 \mathrm{aC}$ & $2,3853 \mathrm{aA}$ & $2,0470 \mathrm{aB}$ & $1,5663 \mathrm{aC}$ \\
\hline Entre vermiculita & $1,3443 \mathrm{aB}$ & $2,3578 \mathrm{aA}$ & 1,4580 b B & $0,7433 \mathrm{~b} \mathrm{C}$ \\
\hline Valor de F para substrato (S) & & $248,00 * *$ & & \\
\hline Valor de F para temperatura $(\mathrm{T})$ & & $205,00 * *$ & & \\
\hline Valor de F para interação (SxT) & & $16,63 * *$ & & \\
\hline $\mathrm{CV}(\%)$ & & 9,56 & & \\
\hline
\end{tabular}

Médias seguidas pela mesma letra, minúscula na coluna e maiúscula na linha, não diferem entre si, pelo teste de Tukey, a 5\%. 
TABELA 6. Massa seca de plântulas de Mimosa caesalpiniaefolia Benth., submetidas a diferentes temperaturas e substratos.

\begin{tabular}{|c|c|c|c|c|}
\hline \multirow{3}{*}{ Substratos } & \multicolumn{4}{|c|}{ Massa seca $(\mathrm{g})$} \\
\hline & \multicolumn{4}{|c|}{ Temperaturas $\left({ }^{\circ} \mathrm{C}\right)$} \\
\hline & 20 & 25 & 30 & $20-30$ \\
\hline Sobre papel & 0,1253 b B & $0,1848 \mathrm{aA}$ & $0,0658 \quad \mathrm{c} \mathrm{C}$ & 0,0760 b C \\
\hline Entre papel & $0,1590 \mathrm{aB}$ & $0,1840 \mathrm{a} A$ & $0,1685 \mathrm{aAB}$ & $0,1193 \mathrm{aC}$ \\
\hline Entre areia & 0,1143 b B & $0,1740 \mathrm{aA}$ & $0,1560 \mathrm{aA}$ & 0,1203 aB \\
\hline Entre vermiculita & 0,1240 b B & $0,1800 \mathrm{aA}$ & 0,1313 b B & 0,0650 b C \\
\hline Valor de F para substrato (S) & & $40,86^{* *}$ & & \\
\hline Valor de $\mathrm{F}$ para temperatura $(\mathrm{T})$ & & $133,73 * *$ & & \\
\hline Valor de F para interação (SxT) & & $16,35^{* *}$ & & \\
\hline CV (\%) & & 9,07 & & \\
\hline
\end{tabular}

Médias seguidas pela mesma letra, minúscula na coluna e maiúscula na linha, não diferem entre si, pelo teste de Tukey, a $5 \%$.

vermiculita proporcionaram os maiores valores de massa fresca, tanto a 20 quanto a $25^{\circ} \mathrm{C}$ e nas temperaturas de 30 e 20 $30^{\circ} \mathrm{C}$, o melhor substrato foi entre areia. Lima \& Garcia (1996) observaram plântulas de Acacia mangium Willd. bem desenvolvidas com o uso do substrato rolo de papel nas temperaturas de $25,25-35$ e $35^{\circ} \mathrm{C}$. Em estudos realizados por Santos et al. (1994) com substratos e profundidades de semeadura, com sementes de Mimosa caesalpiniaefolia, concluíram que os melhores resultados de pesos verde da parte aérea e da raiz foram obtidos com o substrato areia, em todas as profundidades de semeadura $(1,0 ; 2,0$ e $3,0 \mathrm{~cm})$.

O substrato entre papel proporcionou os maiores valores de massa seca a $20^{\circ} \mathrm{C}$; a $25^{\circ} \mathrm{C}$ não houve diferença entre os substratos, e a 30 e $20-30^{\circ} \mathrm{C}$, entre papel e entre areia foram os responsáveis pelos maiores valores de massa seca. O substrato areia também foi responsável pelos maiores valores do peso seco da parte aérea e da raiz das plântulas de Mimosa caesalpiniaefolia quando Santos et al. (1994), avaliaram a influência dos substratos e da profundidade de semeadura no desempenho germinativo e no vigor destas sementes. As temperaturas de 30 ou $35^{\circ} \mathrm{C}$ proporcionaram maior peso seco dos cotilédones nas plântulas de Theobroma grandiflorum (Willd. ex Spreng.) Schum. (Garcia, 1994).

\section{CONCLUSÕES}

- A temperatura de $25^{\circ} \mathrm{C}$ mostrou-se a mais adequada para condução de testes de germinação e vigor em sementes de Mimosa caesalpiniaefolia Benth., independentemente do substrato utilizado;
- o substrato entre papel foi o mais apropriado para avaliação da qualidade fisiológica das sementes;

- a sincronização do processo germinativo é maior no substrato entre papel, independentemente da temperatura utilizada.

\section{AGRADECIMENTOS}

Os autores expressam seus agradecimentos a Professora Sheila Costa de Farias e ao professor Egberto Araújo pela correção do Abstract, ao Eng $^{\circ}$ Agr $^{\circ}$ Antônio Alves de Lima e aos Laboratoristas Pedro Francisco da Silva, Rui Barbosa da Silva e Severino Francisco dos Santos que viabilizaram e execução deste trabalho.

\section{REFERÊNCIAS}

ALBRECHT, J.M.F.; ALBUQUERQUE, M.C.F.E. \& SILVA, M.V.F. Influência da temperatura e do tipo de substrato na germinação de sementes de cerejeira. Revista Brasileira de Sementes, Brasília, v.8, n.1, p.49-55, 1986.

ALBUQUERQUE, M.C.F.E.; RODRIGUES, T.J.D.; MINOHARA, L.; TEBALDI, N.D. \& SILVA, L.M.M. Influência da temperatura e do substrato na germinação de sementes de saguaraji (Colubrina glandulosa Perk. - Rhamnaceae). Revista Brasileira de Sementes, Brasília, v.20, n.2, p.346-349, 1998 .

ALCALAY, N. \& AMARAL, D.M.I. Determinação de métodos de análise de espécies florestais que não constam nas Regras para Análise de Sementes. Roessléria, Porto Alegre, v.4, n.1, p.7583, 1981

ANDRADE, A.C.S. \& PEREIRA, T.S. Efeito do substrato e da temperatura na germinação e no vigor de sementes de cedro - 


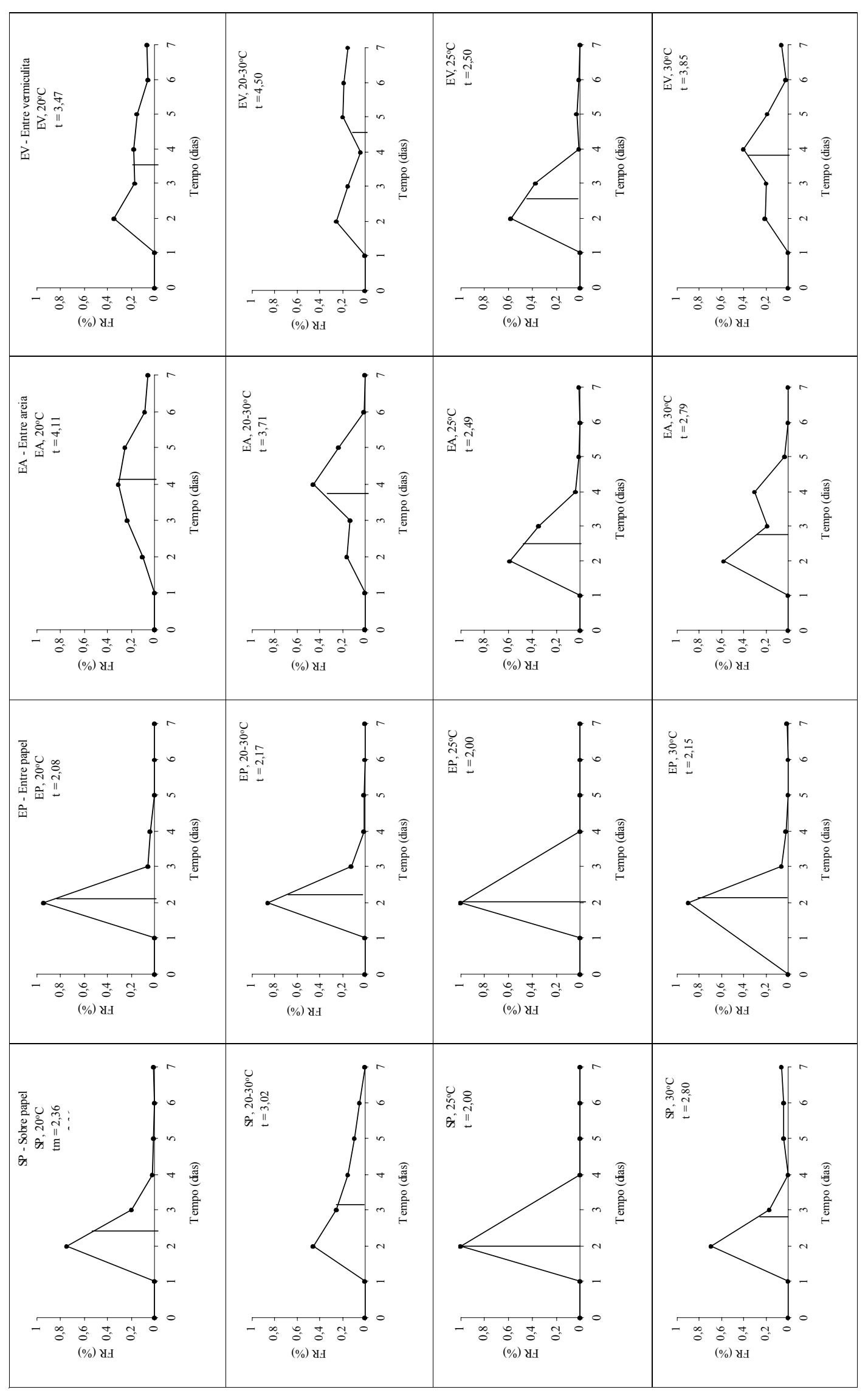

竞

Revista Brasileira de Sementes, vol. 24, $n^{\circ}$ 1, p.169-178, 2002 
Cedrela odorata L. (Meliaceae). Revista Brasileira de Sementes, Brasília, v.16, n.1, p.34-40, 1994.

ANDRADE, A.C.S.; LOUREIRO, M.B.; SOUZA, A.D.O.; RAMOS, F.N. \& CRUZ, A.P.M. Reavaliação do efeito do substrato e da temperatura na germinação de sementes de palmiteiro (Euterpe edulis Mart.). Revista Arvore, Viçosa, V.23, n.3, p.279-283, 1999

BARBOSA, J.M.F.; BARBOSA, L.M.M. \& PINTO, M.M. Influência do substrato, da temperatura e do armazenamento, sobre a germinação de sementes de quatro espécies nativas. Revista Brasileira de Sementes, Brasília, v.10, n.1, p.46-54, 1985.

BASEGGIO, J. \& FRANKE, L.B. Condições para a germinação de sementes de Desmodium incanum DC. Revista Brasileira de Sementes, Brasília, v.20, n.1, p.148-152, 1998

BEWLEY, J.M. \& BLACK, M. Viability, dormancy and environmental control. In: Physiology and biochemistry of seeds. New York: Springer Verlag, 1985. v.2, 328p.

BILIA, D.A.C.; BARBEDO, C.J. \& MALUF, A.M. Germinação de diásporos de canela-preta (Ocotea corymbosa (Meissn.) Mez Lauraceae) em função da temperatura, do substrato e da dormência. Revista Brasileira de Sementes, Brasília, v.20, n.1, p.189-194, 1998.

BORGES, E.E.L. \& RENA, A.B. Germinação de sementes. In: AGUIAR, I.B.; PIÑA-RODRIGUES, F.M.C. \& FIGLIOLIA, M.B. (coords.) Sementes florestais tropicais. Brasília: ABRATES, 1993. cap.3-6, p.83-136.

BRAGA, L.F.; SOUZA, M.P.; BRAGA, J.F. \& SÁ, M.E. Efeito da temperatura na germinação de sementes de purui (Borojoa sorbilis (Duque) Cuatre - Rubiaceae): morfologia das sementes e das plântulas. Revista Brasileira de Sementes, Curitiba, v.21, n.2, p.47-52, 1999

BRASIL. Ministério da Agricultura e Reforma Agrária. Regras para análise de sementes. Brasília: SNDA/DNDV/CLAV, 1992.365p.

CARNEIRO, J.W.P.; MARTINS, E.N. \& BERTONHA, A. Influência da temperatura e de substratos na germinação e no vigor de sementes de stevia (Stevia rebaudiana (Bert.) Bertoni). Revista Brasileira de Sementes, Brasília, v.9, n.1, p.101-106, 1987.

CARNEIRO, J.W.P. Influência da temperatura no desempenho germinativo de um lote sementes de rainha margarida (Caliistephus chinensis Nees - Asteraceae). Revista Brasileira de Horticultura Ornamental, Campinas, v.2, n.2, p.41-47, 1996.

CARVALHO, N.M. \& NAKAGAWA, J. Sementes: ciência, tecnologia e produção. 4.ed. Jaboticabal: FUNEP, 2000. 588p.

CAVALCANTE, A.M.B. \& PEREZ, S.C.J.G.A. Efeitos da temperatura sobre a germinação de sementes de Leucaena leucocephala (Lam.) de Wit. Revista Brasileira de Sementes, Brasília, v.17, n.1, p.1-8, 1995.

CAVALLARI, D.A.; WETZEL, M.M.V.S. \& BATISTA, L.A.R. Substrato e temperatura na germinação de sementes de Gmelina arborea Roxb. Revista Brasileira de Sementes, Brasília, v.14, n.1, p.89-92, 1992

COPELAND, L.O. Principles of seed science and technology. Minnesota: Department of Crop and Soil Sciences Michigan State University, 1976. 369p.
DAVIES, P.J. Plant hormones and their role in plant growth and development. New York: Martinus Nijhoff Publishers, 1988. $681 \mathrm{p}$

FANTI, S.C. \& PEREZ, S.C.J.G.A. Influência do substrato e do envelhecimento acelerado na germinação de olho-de-dragão (Adenanthera pavonina L. - Fabaceae). Revista Brasileira de Sementes, Curitiba, v.21, n.2, p.135-141, 1999.

FIGLIOLIA, M.B.; OLIVEIRA, E.C.\& PIÑA-RODRIGUES, F.C.M. Análise de sementes. In: AGUIAR, I.B.; PIÑA-RODRIGUES, F.C.M. \& FIGLIOLIA, M.B. (coords.). Sementes florestais tropicais. Brasília: ABRATES, 1993. cap.4, p.137-174

FIGUEIREDO, F.J.C. \& POPINIGIS, F. Temperatura para germinação de sementes de malva. Revista Brasileira de Sementes, Brasília, v.2, n.2, p.9-22, 1980.

GARCIA, L.C. Influência da temperatura na germinação de sementes e no vigor de plântulas de cupuaçuzeiro (Theobroma grandiflorum (Willd. ex Spreng.) Schum.) Pesquisa Agropecuária Brasileira, Brasília, v.29, n.7, p.1145-1150, 1994.

GOMES, S.M.S. \& BRUNO, R.L.A. Influência da temperatura e substratos na germinação de sementes de urucum (Bixa orellana L.). Revista Brasileira de Sementes, Brasília, v.14, n.1, p.4750, 1992.

GONÇALVES, E.P; ALVES, E.U.; SILVA, M.A.D. \& VANZOLINI, S. Efeito da temperatura sobre o potencial fisiológico de sementes de sabiá (Mimosa caesalpiniaefolia Benth.) submetidas a debulha mecânica e ao desponte. In: INTERNATIONAL CONGRESS AND EXHIBITION ON FORESTRY, 6, Porto Seguro, 23/26 out. 2000. Anais. Porto Seguro: Instituto Ambiental BIOSFERA, 2000. p.108-109.

HENDRICKS, S.B. \& TAYLORSON, R.B. Variation in germination and amino acid leakage of seeda with temperature related to membrane phase. Plant Physiology, Maryland, v.58, n.1, p.7$11,1976$.

LABOURIAU, L.G. \& PACHECO, A. On the frequency of isothermal germination in seeds of Dolichos biflorus L. Plant \& Cell Physiology, Kioto, v.19, n.3, p.507-512, 1978.

LABOURIAU, L.G. \& VALADARES, M.E.B. On the germination of seeds Calotripes procera Ait. Anais da Academia Brasileira de Ciências, Rio de Janeiro, v.48, n.2, p.263-284, 1976.

LIMA, D. \& GARCIA, L.C. Avaliação de métodos para o teste de germinação em sementes de Acacia mangium Willd. Revista Brasileira de Sementes, Brasília, v.18, n.2, p.180185, 1996.

MAGUIRE, J. D. Speed of germination aid in selection and evaluation for seedling emergence and vigor. Crop Science, Madison, v.2, n.2, p.176-177, 1962.

MALAVASI, M.M. Germinação de sementes. In: PIÑARODRIGUES, F.C.M. (ed.). Manual de análise de sementes florestais. Campinas: Fundação Cargill, 1988. p.25-40

MARCOS-FILHO, J. Germinação de sementes. In: CÍCERO, S.M. MARCOS-FILHO, J. \& SILVA, W.S. Atualização em produção de sementes. Piracicaba: Fundação Cargill, 1986. 11-39p.

MARTINS, C.C.; CARVALHO, N.M. \& OLIVEIRA, A.P. Quebra de dormência de sementes de sabiá (Mimosa caesalpiniaefolia 
Benth.) Revista Brasileira de Sementes, Brasília, v.14, n.1, p.5-8, 1992.

MAYER, A.M. \& POLJAKOFF-MAYBER, A. The germination of seeds. 4.ed. New York: Pergamon Press, 1989. 270p.

MEDEIROS, A.C.S.; ABREU, D.C.A. \& NOGUEIRA, A.C. Efeito da temperatura e do substrato na germinação de sementes de tamanqueiro (Aegiphila sellowiana). Informativo ABRATES, Londrina, v.11, n.2, p.133, 2001.

MIRANDA, P.R.M. \& FERRAZ, I.D.K. Efeito da temperatura na germinação de sementes e morfologia da plântula de Maquira sclerophylla (Ducke) C.C.Berg. Revista Brasileira de Botânica, São Paulo, v.22, n.2 (supl.), p.303-307, 1999.

MUÑOZ, G.; GIRALDO, G. \& SOTO, J.F. Descriptores varietales: arroz, frijol, maíz, sorgo. Colômbia: International Center for Tropical Agriculture (CIAT), 1993. 174p.

NASSIF, S.M.L. \& PEREZ, S.C.J.G.A. Efeitos da temperatura na germinação de sementes de amendoim-do-campo (Pterogyne nitens Tull.). Revista Brasileira de Sementes, Londrina, v.22, n.1, p.1-6, 2000

NOGUEIRA, A.C. Germinação de sementes de Tabebuia chrysotricha (Mart. ex DC.) Standl em diferentes substratos e temperaturas. Informativo ABRATES, Londrina, v.11, n.2, p.274, 2001.

PEREIRA, T.S. \& ANDRADE, A.C.S. Germinação de Psidium guajava L. e Passiflora edulis Sims - efeito da temperatura, substrato e morfologia do desenvolvimento pós-seminal. Revista Brasileira de Sementes, Brasília, v.16, n.1, p.58-62, 1994.

PEREZ, S.C.J.G.A. \& MORAES, J.A.P.V. Influência da temperatura, da interação temperatura-giberelina e do estresse térmico na germinação de algarobeira. Revista Brasileira de Fisiologia Vegetal, Londrina, v.2, n.1, p.41-53, 1990.

PEREZ, S.C.J.G.A.; FANTI, S.C. \& CASALI, C.A. Limites de temperatura e estresse térmico na germinação de sementes de Peltophorum dubium (Spreng) Taubert. Revista Brasileira de Sementes, Brasília, v.20, n.1, p.134-142, 1998.

PIÑA-RODRIGUES, F.C.M. \& VIEIRA, J.D. Teste de germinação. In: PIÑA-RODRIGUES, F.C.M. (ed.). Manual de análise de sementes florestais. Campinas: Fundação Cargill, 1988. p.7090 .

POPINIGIS, F. Fisiologia da semente. 2.ed. Brasília: ABRATES, 1985. 298p.

RANDI, A.M. Efeitos da temperatura, luz e reguladores de crescimento na germinação de Stevia rebaudiana (Bert.) Bertoni. Ciência e Cultura, São Paulo, v.34, n.2, p.235-248, 1981

RÊGO, G.M.; POSSAMAI, E. \& LIMA, R.M.B. Efeito do substrato e da temperatura sobre a germinação e vigor das sementes de jequitibá-rosa (Cariniana legalis (Mart.) - Kuntze Lecythidaeae, em laboratório. Informativo ABRATES, Londrina, v.11, n.2, p.252, 2001a.

RÊGO, G.M.; POSSAMAI, E. \& LIMA, R.M.B. Efeito do substrato e da temperatura sobre a germinação e vigor das sementes de jacandá-da-bahia (Dalbergia nigra Vellozo Leguminoseae-Papilionoidae), em laboratório. Informativo
ABRATES, Londrina, v.11, n.2, p.253, 2001b

RÊGO, G.M.; LIMA, R.M.B. \& POSSAMAI, E. Efeito do substrato e da temperatura sobre a germinação e vigor das sementes de pau-de-alho (Seguieria langsdorffii Moq.) - Phytolaccaceae, em laboratório. Informativo ABRATES, Londrina, v.11, n.2, p.256, 2001c.

REYNOLDS, T. \& THOMPSON, P.A. Effects of kinetin, giberelins and abscisic ácid on the germination of lettuce (Lactuca sativa). Plant Physiology, Copenhangen, v.28, n.3, p.516-522, 1973.

SAKAGUCHI, M. \& KAN, T. As pesquisas japonesas com Stevia rebaudiana (Bert) Bertoni e o steviosídeo. Ciência e Cultura, São Paulo, v.34, n.2, p.235-248, 1982.

SANTOS, D.S.B.; SANTOS-FILHO, B.G.; TORRES, S.B.; FIRMINO, J.L. \& SMIDERLE, O.J. Efeito do substrato e profundidade de semeadura na emergência e desenvolvimento de plântulas de sabiá. Revista Brasileira de Sementes, Brasília, v.16, n.1, p.50-53, 1994.

SANTOS, C.M.; SOUZA, G.R.L.; SILVA, J.R. \& SANTOS, V.L.M. Efeito da temperatura e do substrato na germinação de sementes do maracujá (Passiflora edulis Sims f. flavicarpa Deg.). Revista Brasileira de Sementes, Curitiba, v.21, n.1, p.1-6, 1999.

SANTOS, S.R.G. \& AGUIAR, I.B. germinação de sementes de branquilho (Sebastiania commersoniana (Baill.) Smith \& Downs) em função do substrato e do regime de temperatura. Revista Brasileira de Sementes, Londrina, v.22, n.1, p.120 126, 2000.

SILVA, A. \& AGUIAR, I.B. Germinação de sementes de canelapreta (Ocotea catharinensis Mez - Lauraceae) sob diferentes condições de luz e de temperatura. Revista do Instituto Florestal, São Paulo, v.10, n.1, p.17-22, 1998.

TAKAHASHI, L.; MELGES, E. \& CARNEIRO, J.W.P. Desempenho germinativo de sementes de Stevia rebaudiana (Bert.) Bertoni sob diferentes temperaturas. Revista Brasileira de Sementes, Brasília, v.18, n.1, p.6-9, 1996.

TAMBELINI, M. Tratamentos pré-germinativos e aspectos ecofisiológicos na germinação de sementes de Stryphnodendron polyphyllum Mart. São Carlos: UFSCar, 1994. 112p. (Dissertação Mestrado).

TORRES, S.B. \& MELLO, V.D.C. Germinação de sementes de gliricidia (Gliricidia sepium (Jacq.) Steud). Ciência Rural, Santa Maria, v.24, n.3, p.631-632, 1994.

TORRES, S.B.; FIRMINO, J.L. \& MELLO, V.D.C. Germinação de sementes de sabiá (Mimosa caesalpiniaefolia Benth.) e algarobeira (Prosopis juliflora (Sw.) DC.). Ciência Rural, Santa Maria, v.24, n.3, p.629-630, 1994.

VIEIRA, R.D. \& CARVALHO, N.M. Testes de vigor em sementes Jaboticabal: FUNEP, 1994. 164p.

VILLAGOMEZ, A.Y; VILLASENOR, R.R \& SALINAS, M.J.R Lineamento para el funcionamento de um laboratório de semillas. México: INIA, 1979. 91p.

ZPEVAK, F.A. Efeitos do ácido abscísico, potencial hídrico, temperatura e tratamentos para quebra de dormência na germinação de sementes de Dimorphandra mollis Benth. São Carlos: UFSCar, 1994. 104p. (Dissertação Mestrado). 